amount almost equal to the volume of the brain-could be injected into the ventricle within two hours; after each injection the pressure returned to the original level. Immediate post-mortem did did not reveal any œdema, so that rapid and complete absorption must have taken place directly into the blood-stream through the choroid plexus. On the other hand, ventricular fluid could be withdrawn repeatedly without lowering the ultimate ventricular pressure, if the salt content so withdrawn was replaced in the form of hypertonic saline solution. In all these experiments the choroid plexus behaved in a manner consistent with the conception that it functions as a semi-permeable membrane, permitting the passage of fluid in either direction in accordance with the laws of osmosis.

G. W. T. H. FLEMING.

The Galvanic Skin Reflex. (Arch. of Neur. and Psychiat., Fuly, 1931.) Syz, H. C., and Kinder, E. F.

This is a study of the content of the stimulus words eliciting psycho-galvanic responses in persons belonging to different psychopathological groups and in normal individuals. The authors found in the abnormal groups an emphasis on words relating to personal characteristics, to terms which imply a valuation of one's self, often with an undertone of expected failure, inferiority or guilt. There was a slightly greater emphasis on depressive topics among the depressed patients. The paranoid schizophrenics showed almost the same general reaction as the depressed ones. As the psycho-galvanic response may be taken as an indicator of emotional activity, it appeared that there was more emotional activity in the schizophrenic than in the depressive group. The results go to confirm that schizophrenic development often does not mean a decrease of emotional assets and activities, but rather a disturbance in the constellation and application of emotional trends. In the normal persons there is less emphasis on egocentric anxieties and concerns, but there is a marked predominance of reaction to sex words; this is due largely to a socially induced sensitiveness.

G. W. T. H. FLEMING.

\title{
2. Psychology and Psycho-Pathology.
}

Symbolism as a Mental Process. (Psyche, No. 46, October, 1931.) McConnel, Ursula Hope.

A study of the Totem in the Wik-Munkan tribe, with a critical survey of the Freudian interpretation of the symbolism of primitive societies.

S. M. Coleman.

A New Approach to the Problem of Psychoneurosis in Childhood. (Brit. Fourn. Med. Psychol., November, I93I.) Lowenfeld, M. F.

Adopting the standpoint that a neurosis represents the reaction of the whole child to its whole circumstances, Miss Lowenfeld 